\title{
Guidelines for the Collaborative Management of Persons with Diabetes Mellitus by Eye Care Professionals
}

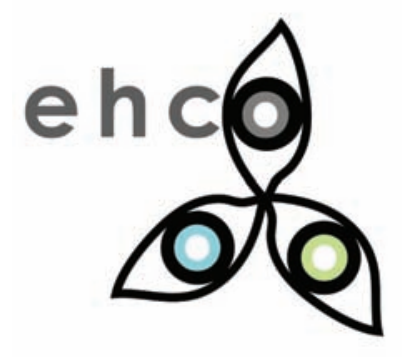

\section{EYE HEALTH COUNCIL OF ONTARIO SEPTEMBER 23 ${ }^{\mathrm{RD}}, 2011$}

\section{Background}

Diabetes is a disease that is growing rapidly in both incidence and prevalence in Ontario (dramatically exceeding the global estimates of the World Health Organization), and poses a major public health challenge on many fronts. ${ }^{1}$ More specifically, diabetic retinopathy is the most common cause of new cases of legal blindness in people of working age. 2,12 Approximately $12 \%$ of new cases of blindness are caused by diabetic retinopathy, and people with diabetic retinopathy are 25 to 29 times more likely than the general population to become blind within four years. ${ }^{3,13}$ As many as $20 \%$ of patients newly diagnosed with Type 2 Diabetes ( $90 \%$ of cases of diabetes are Type 2 ), have some evidence of diabetesrelated eye disease at the time of diagnosis, and approximately $5 \%$ will need immediate treatment to help prevent vision loss. Within seven years of diagnosis, $50 \%$ of patients with Type 2 Diabetes will develop diabetes-related changes to the eye. By 15 years, this number increases to as many as $85 \%$, with $25 \%$ requiring treatment. ${ }^{3}$ Essentially $100 \%$ of patients with Type 1 Diabetes will exhibit some diabetes-related eye disease 15 to 20 years after diagnosis. ${ }^{3,8}$ Further, the vascular changes that occur within the eye are predictive of vascular changes occurring elsewhere in the body. 6,7

Vision loss from diabetic retinopathy is best treated (and may be prevented) if caught in time. ${ }^{4}$ Unfortunately, data from the U.S. and Australia show that $50 \%$ of people with diabetes are not receiving regular eye examinations. 9,10 These numbers are staggering when extrapolated to the approximately three million Canadians

\section{Eye Health Council of Ontario (EHCO)}

It has long been clear to those involved in eye health care in Ontario that there is a need for a venue to promote inter-professional collaboration to optimize the provision of eye care and disseminate these concepts to appropriate stakeholders. Approximately six years ago, an informal Eye Care Council was created by the Ontario Association of Optometrists and Ontario Medical Association Section on Ophthalmology for this purpose. This has since evolved into the Eye Health Council of Ontario (EHCO).

The inaugural meeting of EHCO took place on December 3, 2010, following the March 31, 2010 recommendations of the Health Professions Regulatory Advisory Council (HPRAC) "Report to the Minister of Health and Long-Term Care on Inter-professional Collaboration Among Eye Care Health Professionals." This report envisioned a Council composed of optometrists and ophthalmologists working together, similar to the innovative model in Nova Scotia, building upon the foundation already established in Ontario.

The mandate of EHCO is to support the provision of accessible, quality eye care to the population of Ontario by ensuring the most effective use of the continuum of eye care professionals in the interests of patient safety, quality of care, and cost-effective delivery.

EHCO will also provide a unified voice for eye care issues at the Ministry of Health and Long-Term Care (MOHLTC), and serve as a mechanism to develop common collaborative guidelines for patient care, and as an ideal atmosphere for inter-professional collaboration outside the regulatory framework. Membership includes fourteen individuals from both ophthalmology and optometry representing academic, political and regulatory bodies of each profession. Both professions agreed to a governance structure wherein two co-chairs shall oversee the meetings; one chair shall be an optometrist, the other an ophthalmologist. Items require a 2/3 majority vote to be approved by EHCO. The council shall meet four times annually and host an extended meeting once per year, inviting all appropriate stakeholders (i.e. opticians, industry, CNIB, family physicians, etc). There are two observers from each College (College of Physicians and Surgeons of Ontario (CPSO) and College of Optometrists of Ontario 
Preventing blindness in people with diabetes is uniquely cost-saving and cost-effective. There are few cases in health care that are so self-evident." '

- JC Javitt, MD, MPH "Blindness: We Know What It Costs! Now What?" Cost of Blindness Symposium ${ }^{1}$

currently living with diabetes (onethird of whom are unaware they have diabetes); a number predicted to increase to 3.7 million by $2020 .^{5}$ Canada's Aboriginal people have a rate of diabetes nearly five times that of non-Aboriginal people, and are at a greater risk for vision loss from diabetes and its ocular complications than any other ethnic group in Canada. ${ }^{5}$

Eye care providers face a challenge in the management and coordination of care for patients with diabetes. The delivery of eye care must provide cost effective and efficient use of resources to minimize preventable vision loss.

\section{Effectiveness of current methods of assessment for diabetic retinopathy (DR)}

Assessment plays an important role in early detection and intervention to prevent the progression of diabetic retinopathy (DR). Low vision/blindness is substantially reduced among people with diabetes who receive recommended levels of care. ${ }^{15}$ Despite the high level of efficacy, and both clinical and cost effectiveness of DR assessment and treatment, problems remain with assessment and treatment compliance. Many people with diabetes do not access regular eye examinations and the barriers that prevent them from attending for assessment are numerous.
Successful distribution of comprehensive guidelines to ophthalmologists and optometrists in many locations have not resulted in any significant impact on management practices for DR and recommendations for assessment and examination have been poorly followed. ${ }^{16,17,18,19}$

In Canada, only $32 \%$ of patients with Type 2 Diabetes meet the Canadian Diabetes Association ${ }^{20,21}$ guideline-recommended schedule of evaluation for diabetic retinopathy. ${ }^{22}$ A study that examined assessment patterns in five Canadian provinces has shown that $32 \%$ of the population with diabetes had not had an eye examination in the last 2 years and that another $32 \%$ had never had an eye examination for DR..$^{23}$

Factors affecting non-adherence to recommended guidelines are numerous. They include lack of awareness that diabetic retinopathy can lead to blindness or that severe retinopathy can be asymptomatic. ${ }^{24}$

\section{(EHCO cont'd.)}

(COO)). As per HPRAC's recommendation, a senior representative from MOHLTC participates as an observer on EHCO, providing advice to the Council and information to the Ministry and Minister on Council activities.

The ultimate goal of EHCO is the delivery of accessible, safe, quality eye care by the provider best positioned to do so in their area of the Province. In doing so, wait times will decrease, quality of care will improve, and adverse outcomes will be minimized. The independent professional Colleges (CPSO and COO) will continue to ensure public safety through regulation of their professional members. The Council, through knowledge transfer and cooperative sharing of best practice information, will be positioned to provide valuable information to all participants, including the Ministry, to continually improve the delivery of eye care in Ontario.

On September 23, 2011, the members of the Eye Health Council of Ontario unanimously passed their first inter-professional collaborative guideline, focusing on the care of patients with diabetes mellitus. We trust that these guidelines are an important first step in improving eye health care delivery for patients living with diabetes - and ultimately, for all Ontarians.

Respectfully submitted,

Dr. Thomas-A. Noël BSC OD

Co-Chair EHCO

Chair of Registration

Provincial Council Member

College of Optometrists of Ontario

Ottawa, ON

SherifEl-Defrawy MD PhD FRCSC

Co-Chair EHCO

Professor and Chair

Dept of Ophthalmology, Queen's University

Ophthalmologist in Chief

Hotel Dieu and Kingston General Hospitals

Kingston, ON 
Limited access to eye care professionals, particularly in remote areas $25,26,27$, can play a significant role. Fear of laser treatment, guilt about poor control causing retinopathy, the inconvenience of regular attendance ${ }^{24}$ and limited personal mobility due to poor overall health and self-reported apathy ${ }^{28}$ may also deter patients from attending assessment appointments.

Primary care provider recommendation about the necessity of a regular eye examination is the most significant predictor of assessment for diabetic retinopathy and once such a recommendation is given, the assessment rate improves. ${ }^{29}$ Thus, all physician/allied health staff encounters with individuals with diabetes should be used as an opportunity for education on the need for regular eye assessment and on risk factors associated with DR.

Evidence $^{30}$ indicates that increasing patient awareness of diabetic retinopathy, improving provider and practice performance, improving healthcare system infrastructure processes to make attendance more convenient for patients, using patient recall systems and better outreach to disadvantaged populations can significantly improve the rates of assessment for diabetic retinopathy.

Any chosen assessment strategy or program needs sufficient resource allocation and access to information technology to ensure comprehensive coverage and compliance with qualityassurance standards. ${ }^{31}$

\section{Goal}

The goal of these guidelines is to coordinate the services of ophthalmologists, optometrists, family physicians, physician specialists, nurse practitioners and allied health staff in the management of patients with diabetes, thereby ensuring the most effective use of these professionals in the interest of patient safety, quality of care, accessibility and cost effectiveness.

\section{Roles}

\section{Primary Care Providers:} Family Physician/Physician Specialist/Nurse Practitioner/ Allied Health Staff

The first step in preventing ocular complications from diabetes is identifying the population at risk. Primary care providers, including family physicians, are responsible for identifying patients with diabetes and play a key role in the care and treatment process. As the coordinators of patient care, primary care providers should promptly refer any newly diagnosed patient with Type 2 Diabetes for an assessment by an optometrist (or ophthalmologist). Patients over the age of puberty with Type 1 Diabetes need to be referred within five years of their diagnosis with diabetes.

Pediatric patients with Type 1 Diabetes should be referred for a comprehensive eye examination once the child has reached the age of 10 , or has had diabetes for at least three years. Ideally, an ophthalmologist should perform this initial examination. Once the patient has reached the age of 13 , in the absence of retinopathy, the patient should be followed by an optometrist (or ophthalmologist) on an annual basis.

Family physicians also need to ensure that their established patients with either Type 1 or Type 2 Diabetes, but without retinopathy, are assessed by an optometrist (or ophthalmologist) annually. Ideally, each referral would be accompanied by fasting blood glucose and HbA1c levels.

The above outlined pattern of referral to an optometrist is intended to improve patient access to timely and consistent surveillance for eye disease related to diabetes. While the Eye Health Council would recommend that initial referrals be directed to an optometrist, it is not the intent to restrict direct access to an ophthalmologist through a requirement to first see an optometrist.

\section{Recommendations}

Refer any patients over the age of puberty with Type 1

Diabetes within five years of their diagnosis with diabetes for an assessment by an optometrist (or ophthalmologist).

Refer any patient newly diagnosed with Type 2 Diabetes for an assessment by an optometrist (or ophthalmologist). The patient should be seen within six months of the referral.

Refer any pediatric patient with Type 1 Diabetes for a comprehensive eye examination once the child has reached the age of 10 , or has had diabetes for at least three years. Ideally, an ophthalmologist should perform this initial examination. Once 
the patient has reached the age of 13 , in the absence of retinopathy, the patient should be followed by an optometrist (or ophthalmologist) on an annual basis.

- At every visit, a patient with diabetes should be asked about their liaison with an optometrist or ophthalmologist to ensure appropriate monitoring.

- As mentioned later in this document, the optometrist and ophthalmologist will ensure that the next regular visit for their patient with diabetes is arranged, and will correspond with all appropriate physicians and allied health staff with ocular updates on the patient.

\section{Optometrist}

Optometrists will assess patients according to established protocols (see Specific Recommendation section that follows) for ocular complications of diabetes and should provide a report of the findings at the initial patient encounter, and thereafter when clinically indicated, to the family physician/primary care provider. It is helpful to provide an annual update if the patient is being seen more frequently. In cases where diabetic eye disease is detected, optometrists should use generally accepted criteria when managing and/or referring the patient to an ophthalmologist or retinal specialist. Referral for subsequent care should include a report to the ophthalmologist and family physician.

\section{Ophthalmologist}

Ophthalmologists are responsible for assessing and (if necessary) treating diabetic eye disease to prevent, minimize or restore vision loss. Patients with diabetic eye disease, who remain at high risk of vision loss, should continue to be monitored by the ophthalmologist. The ophthalmologist should provide a report of the findings at the initial patient encounter, and thereafter when clinically indicated, to the family physician/ primary care giver and optometrist. It is helpful to provide an annual update if the patient is being seen more frequently.

All professionals share the common role of ensuring their patients are educated with respect to diabetes in general, and their specific clinical situation.

\section{Initial / Ongoing Assessment}

\section{Initiation of assessment in people with Type 1 Diabetes}

In Type 1 Diabetes, sight-threatening retinopathy is very rare in the first five years of diabetes or before puberty. ${ }^{32}$ However, almost all patients with Type 1 Diabetes develop retinopathy over the subsequent two decades ${ }^{33}$ and duration of diabetes is strongly associated with the development and severity of DR. ${ }^{34,35,36,37}$

Based on the available evidence, assessment for diabetic retinopathy in post-pubertal individuals should be initiated within five years of diagnosis.

For pre-pubertal individuals, assessment should be initiated at age 10 or within three years of diagnosis, whichever comes first.

\section{Initiation of assessment in people with Type 2 Diabetes}

Duration of diabetes is the strongest risk factor linked to the development of DR. ${ }^{38,39,40,41,42}$. DR risk is continuous with no evident glycemic or blood pressure threshold. ${ }^{75}$

At the time diabetes is diagnosed, up to $3 \%$ of patients with diabetes over age 30 have CSME or highrisk DR findings. ${ }^{43,44}$ After a 10 -year duration of diabetes, $7 \%$ of persons with diabetes were shown to have retinopathy; this number increased to $90 \%$ after 25 years. Proliferative disease was found in $20 \%$ of patients after 20 years of diabetes. ${ }^{45}$ DR prevalence was shown to be lower in patients diagnosed with diabetes after the age of 70 years, and patients with DR had a significantly higher median duration of diabetes (5.0 years) than those without DR (3.5 years). ${ }^{46}$

The interval between the onset of symptoms and diagnosis in patients with Type 2 Diabetes is seven years. Given this and the foregoing information, retinopathy assessment for patients with Type 2 Diabetes should be initiated at the time of diagnosis.

\section{Assessment intervals for people with diabetes}

Since 1985, lower rates of progression to PDR and of severe visual loss from DR have been reported. This may reflect an increased awareness of retinopathy risk factors, earlier identification and care for patients with retinopathy as well as 
improved glucose, blood pressure, and serum lipids management. ${ }^{47}$

\section{Type 1 Diabetes}

The EURODIAB Prospective Complications Study found that diabetes duration, age at onset before age 12 years, and metabolic control were significant predictors of progression, even when adjusted for presence of baseline retinopathy. ${ }^{48}$

\section{Specific}

\section{Recommendations}

\section{NO RETINOPATHY}

\section{Type 1 Diabetes}

Available evidence indicates that an annual assessment needs to be performed by an optometrist (or ophthalmologist, or telemedicine screening if those doctors are not accessible).

\section{Type 2 Diabetes}

In the absence of any DR, assessment intervals of 19 to 24 months, as compared with intervals of 12 to 18 months, are not associated with increased risk of referable retinopathy, ${ }^{49}$ and biennial screening has been shown to be safe and effective with no person progressing from having no retinopathy to sight-threatening retinopathy in under two years. ${ }^{50}$ This approach reduces the number of assessments by more than $25 \%$, considerably reducing health costs, strain on resources and relieving patients with diabetes from unnecessary examinations..$^{51}$ However, screening intervals of more than 24 months are associated with an increased risk of sight-threatening $\mathrm{DR}^{49}$ The overriding concern, however, is that a move away from annual examinations will result in patients being lost to proper follow-up. This is especially true for people with poor access to care. Given that the current standard of care for people with Type 1 Diabetes is annual examinations, this will be the recommendation of these guidelines for patients with Type 2 Diabetes. Biennial follow-up may be suggested for those patients who can be relied upon to recognize the need for recall after 24 months, or for offices that are able to recall patients effectively at the 2-year mark.

Annual assessment of patients with Type 2 Diabetes with no retinopathy needs to be performed by an optometrist (or ophthalmologist, or telemedicine screening if those doctors are not accessible).

\section{PREGNANT WOMEN WITH DIABETES}

Before attempting to become pregnant, women with Type 1 or Type 2 Diabetes should undergo an ophthalmic evaluation by an optometrist or ophthalmologist. Repeat assessments should be performed during the first trimester, as needed during pregnancy, and again within the first year postpartum. ${ }^{76}$ This guideline does not apply to women who develop gestational diabetes, because such individuals are not at increased risk for diabetic retinopathy.

\section{MINIMAL RETINOPATHY: Mild NPDR}

- Several microaneurysms

- Visual acuity of $6 / 6$ or better (unless other known cause of decreased vision)

Annual follow-up of patients with mild NPDR by an optometrist (or ophthalmologist, or telemedicine screening if those doctors are not accessible).

\section{MODERATE RETINOPATHY:} Moderate NPDR

- Intraretinal hemorrhages

- Hard exudates

- Nerve fibre layer infarcts/cotton wool spots (CWS)

Consider referral of a patient with moderate NPDR to an ophthalmologist (or retinal specialist) if there is any concern about DME, CSME, or other treatable disease. Assessment of patients with moderate NPDR by an eye care professional (optometrist or ophthalmologist) needs to occur at least every six months.

\section{SEVERE RETINOPATHY:}

\section{Severe NPDR}

Severe NPDR includes all features of moderate NPDR, plus any one of the following:

- Intraretinal hemorrhages $(\geq 20$ in each of 4 quadrants)

- Venous beading ( 2 or more quadrants)

- Arteriolar narrowing 
Intraretinal microvascular abnormalities - IRMA (1 or more quadrant(s))

Very severe NPDR is defined as any 2 of the criteria for severe NPDR.

Referral to a retinal specialist (or ophthalmologist) for possible treatment. Assessment by an ophthalmologist every 2 to 4 months. Once stabilized, the patient requires follow-up by either an optometrist or ophthalmologist (or retinal specialist) so that assessment occurs at least every six months.

\section{DIABETIC MACULAR EDEMA: DME, CSME}

Clinically significant macular edema (CSME) is defined as ${ }^{74}$ :

- Retinal thickening at or within 500 microns of the fovea

- Hard exudates at or within 500 microns of the fovea (if adjacent retina is thickened)

- Retinal thickening 1 disc diameter or larger if within $1 \mathrm{disc}$ diameter of the fovea

Referral to a retinal specialist (or ophthalmologist) for treatment (laser, IVI). Follow-up by treating ophthalmologist until DME has stabilized or resolved. Once stabilized, the patient requires follow-up by either an optometrist or ophthalmologist (or retinal specialist) so that assessment occurs at least every six months.

\section{PROLIFERATIVE DIABETIC RETINOPATHY: PDR}

Neovascularization of the disc - NVD

Neovascularization elsewhere NVE

- Vitreous/pre-retinal hemorrhage

- Neovascularization of the iris NVI (anterior segment neovascularization)

Referral to a retinal specialist (or ophthalmologist) for treatment (laser, IVI, vitrectomy). Follow-up by treating ophthalmologist until regression. Once stabilized, the patient requires follow-up by either an optometrist or ophthalmologist (or retinal specialist) so that assessment occurs at least every six months.

\section{Assessment Tools}

Patient assessment by both ophthalmologist and optometrist includes a full examination of all ocular structures and a commentary on any diabetes associated ocular complications, rather than only diabetic retinopathy. Clinical examination to detect and assess DR and its severity may be performed with slit lamp biomicroscopy, ophthalmoscopy or retinal photography. It should include measurement of visual acuity, and pupils should normally be dilated for the fundus examination. Adequate sensitivity and specificity in performing the assessments are required for the examiners in all assessment processes. Minimum sensitivity required for DR has been set to $80 \%{ }^{53,54}$ or, in the case of repeated examinations that would detect DR missed at earlier examinations, to $60 \%$. ${ }^{55}$ Specificity levels of $90-95 \%$ and technical failure rates of $5-10 \%$ are considered appropriate. ${ }^{54}$

\section{Biomicroscopy}

Slit lamp biomicroscopy with a non-contact fundus lens after pupil dilation is the currently accepted standard of practice for DR detection (sensitivity of $87.4 \%$ and specificity of $94.4 \%$ ), and is preferred over direct ophthalmoscopy, which has lower and more variable sensitivity even in the hands of an experienced examiner (sensitivity 56-98\%, specificity 62100\%). ${ }^{56}$ Training should ensure examiners of sufficient diagnostic accuracy and adequate sensitivity and specificity. ${ }^{54,57}$ Single-field retinal photography or optical coherence tomography are not replacements for a proper dilated retinal examination.

\section{Retinal Photography}

Stereoscopic seven-field fundus photography evaluated by a trained grader is the "gold standard" method of detecting DR and has been used in most of the large clinical trials in this area. However, it is costly and time consuming and is used rarely in routine practice. Single-field retinal photography can be useful for documentation and follow-up purposes as a part of a comprehensive examination by an optometrist or ophthalmologist.

\section{Telemedicine}

Digital retinal photography is increasingly being used in screening for DR. It is not a substitute for a comprehensive eye examination, 
but in circumstances where there is no optometrist or ophthalmologist available, there is level I evidence that it can serve as a screening tool for diabetic retinopathy. Patients identified as having retinopathy through this method should be referred to an optometrist or ophthalmologist for further evaluation and management. ${ }^{58,59,60,61,62,63}$

Fundus imaging has the additional advantage of being perceived by patients as a valuable educational resource. ${ }^{24}$ It can be performed with dilated pupils or with non-mydriatic cameras through non-dilated pupils. ${ }^{64}$ The chosen technology, along with the number of camera fields taken, will influence sensitivity of screening. ${ }^{65}$

\section{Fluorescein Angiography (FA)}

Fluorescein angiography has no role in screening for DR, but is essential in late-stage disease to detect and delineate retinal ischemia. It is an invasive examination with an inherent albeit small risk of significant side effects, some mild and transient, some severe (such as anaphylaxis or cardiac arrest).

\section{Optical Coherence Tomography (OCT)}

Optical coherence tomography is a non-contact, non-invasive technique that produces cross-sectional images of the retina and optic disc similar to histological sections. It has an axial resolution of $5 \mu \mathrm{m}$ with newer instruments and provides qualitative and quantitative data that correlate well with fundus stereophotography or biomicroscopy to diagnose diabetic macular edema. It has good reproducibility and provides accurate measurements of retinal thickness. ${ }^{67,68}$

OCT appears useful to detect macular thickening in the early stages of diabetic retinopathy in patients with retinopathy and no clinical evidence of macular edema, enabling closer follow-up for early DME. ${ }^{69,70}$ However, OCT does not help in predicting which eyes with subclinical DME will progress to clinically significant DME. ${ }^{71}$

OCT is an effective qualitative and quantitative method for detecting early macular thickening and following progression or regression of macular edema over the course of treatment, and has been incorporated as a routine measure in numerous ongoing studies of new treatments for DR.

Current data suggest that there is little reason to routinely obtain OCT in eyes with diabetes and no retinopathy or mild to moderate diabetic retinopathy when clinical examination fails to show macular edema. ${ }^{72}$ However, OCT should be strongly considered when any change in macular architecture, or any unexplained change in bestcorrected acuity, is encountered.

\section{Conclusion}

The coordination of health care resources is essential in the care and treatment of patients at risk for ocular complications from diabetes. Timely optometric assessment of newly diagnosed diabetic patients will identify patients at risk for diabetic eye disease. Early intervention and treatment of eye disease through appropriate and timely referral for ophthalmologic care will assist in the preservation of quality vision for patients with diabetes. Inter-professional guidelines and generally accepted management and referral criteria will ensure appropriate coordination of care and the most effective use of health professional resources.

\section{References}

1. Lipscombe L. Hux J. Trends in diabetes prevalence, incidence and mortality in Ontario, Canada 1995-2005: a population-based study. Lancet. 2007; 369 (9563): 750-756.

2. Klein R, Klein BEK. Vision disorders in diabetes. In: National Diabetes Data Group. Diabetes in America, 2nd ed. National Institutes of Health. 1995; (951468): 293-338.

3. Javitt JC, Canner JK, Sommer A. Cost effectiveness of current approaches to the control of retinopathy in type I diabetes. Ophthalmology. 1989; 96: 255264.

4. Ferris F. How effective are treatments for diabetic retinopathy? JAMA. 1993. 269: 1290-1291.

5. CDA. http://www.diabetes. $\mathrm{ca} /$ documents/about-diabetes/ PrevalanceandCost_09.pdf

6. Bowyer NK. Diabetic Retinal Changes Linked to Amputation. Review of Optometry. 2003. December.

7. Moss SE, Klein R, Klein BEK, Wong TY. Retinal vascular changes and 20 year incidence of lower extremity amputations in a cohort with diabetes. Arch Intern Med. 2003. 163: 2505-2510.

8. CNIB. Eye conditions. Diabetes and the eye. Toronto: CNIB. http://www.cnib. ca/eng/eye_con/cospubs/diabetes.htm

9. Commonwealth of Australia. NHMRC Clinical Practice Guidelines (1997) Management of diabetic retinopathy, Commonwealth of Australia Publication No 2142, Commonwealth Department of Health and Family Services. 1997. Canberra.

10. Wang F, Javitt JC. Eye care for elderly Americans with diabetes mellitus. Failure to meet current guidelines. Ophthalmology. 1997. 103. 1744-1750. 
11. A Clear Vision. Solutions to Canada's Vision Loss Crisis, Toronto, ON: Canterbury Communications; 2004. http://www.costofblindness.org

12. Ontario Ministry of Health and LongTerm Care. Diabetes Task Force, Report to the Minister of Health and Long-Term Care. 2004. http://www. health.gov.on.ca/english/public/pub/ ministry_reports/diabetes_taskforce/ diabetes_ta skforce.html

13. Kahn HA, Hillier R. Blindness caused by diabetic retinopathy. Am J Ophthalmol. 1974. 78: 58-67.

14. International Council of Ophthalmology. International Standards: For Vision, Eye Care and Ophthalmology. http://www.icoph. org/standards/index.html

15. Sloan FA, Grossman DS, Lee PP. Effects of receipt of guidelinerecommended care on onset of diabetic retinopathy and its progression. Ophthalmology. 2009 Aug;116(8):151521, 1521.e1-3.

16. Schoenfeld ER, Greene JM, Wu SY, Leske MC. Patterns of adherence to diabetes vision care guidelines: baseline findings from the Diabetic Retinopathy Awareness Program. Ophthalmology 2001 Mar;108(3):563-71.

17. Lee SJ, Livingston PM, Harper CA, McCarty CA, Taylor HR, Keeffe JE.Compliance with recommendations from a screening programme for diabetic retinopathy. Aust N Z J Ophthalmol. 1999 JunAug;27(3-4):187-9.

18. Lee SJ, Sicari C, Harper CA, Livingston PM, McCarty CA, Taylor HR, Keeffe JE.Examination compliance and screening for diabetic retinopathy: a 2-year follow-up study.Clin Experiment Ophthalmol. 2000 Jun;28(3):149-52. PMID: 10981784

19. McCarty CA, Wright S, McKay R, Taylor KI, Keeffe JE; Working Group on Evaluation of NHMRC Diabetic Retinopathy Guidelines. Changes in management of diabetic retinopathy by Australian ophthalmologists as a result of the NHMRC clinical guidelines. Clin Experiment Ophthalmol. 2001 Aug;29(4):230-4

20. Clark HD, van Walraven C, Code C, Karovitch A, Keely E. Diabetes Care.
Did publication of a clinical practice guideline recommendation to screen for type 2 diabetes in women with gestational diabetes change practice? 2003 Feb;26(2):265-8.

21. Woo V; CDA 2008 Clinical Practice Guidelines Steering Committee. Medical management of hyperglycemia in type 2 diabetes: a consensus algorithm for the initiation and adjustment of therapy: a consensus statement of the American Diabetes Association and the European Association for the Study of Diabetes: response to Nathan et al. Diabetes Care. 2009 Mar;32(3):e34; author reply e37-8. No abstract available.

22. Sloan FA, Brown DS, Carlisle ES, Picone GA, Lee PP. Monitoring visual status: why patients do or do not comply with practice guidelines. Health Serve Res. 2004 Oct;39(5):1429-48.PMID: 15333116

23. Boucher MC, Earaches G, GarciaSalinas R, Kearny A, Maberley D, Olivier $\mathrm{S}$, Oh M, Stockl F. Teleophthalmology screening for diabetic retinopathy through mobile imaging units within Canada. Can J Ophthalmol. 2008 Dec;43(6):658-68.

24. Lewis K, Patel D, Yorston D, Charteris D. A qualitative study in the United Kingdom of factors influencing attendance by patients with diabetes at ophthalmic outpatient clinics. Ophthalmic Epidemiol. 2007 NovDec;14(6):375-80.PMID: 18161611

25. Maberley DA, Koushik A, Cruess AF. Factors associated with missed eye examinations in a cohort with diabetes. Can J Public Health. 2002 MayJun;93(3):229-32.PMID: 12050993

26. Mukamel DB, Bresnick GH, Wang Q, Dickey CF. Barriers to compliance with screening guidelines for diabetic retinopathy. Ophthalmic Epidemiol. 1999 Mar;6(1):61-72.

27. Leese GP, Boyle P, Feng Z, EmslieSmith A, Ellis JD. Screening uptake in a well-established diabetic retinopathy screening program: the role of geographical access and deprivation. Diabetes Care. 2008 Nov;31(11):2131-5. Epub 2008 Aug 26.PMID: 18728235

28. Puent BD, Nichols KK. Patients' perspectives on noncompliance with diabetic retinopathy standard of care guidelines. Optometry. 2004 Nov;75(11):709-16.

29. Dervan E, Lillis D, Flynn L, Staines A, O'Shea D. Factors that influence the patient uptake of diabetic retinopathy screening.2008 Dec;177(4):303-8. Epub 2008 Jul 19.

30. Zhang X, Norris SL, Saadine J, Chowdhury FM, Horsley T, Kanjilal $\mathrm{S}$, Mangione CM, Buhrmann R. Effectiveness of interventions to promote screening for diabetic retinopathy. Am J Prev Med. 2007 Oct;33(4):318-35. Review.PMID: 17888859

31. Goldstein DE, Blinder KJ, Ide CH, Wilson RJ, Wiedmeyer HM, Little RR, England JD, Eddy M, Hewett JE, Anderson SK. Glycemic control and development of retinopathy in youth-onset insulin-dependent diabetes mellitus. Results of a 12-year longitudinal study. Ophthalmology. 1993 Aug;100(8):1125-31; discussion 1131-2.

32. Orchard TJ, Dorman JS, Maser RE, Becker DJ, Drash AL, Ellis D, LaPorte RE, Kuller LH.Prevalence of complications in IDDM by sex and duration. Pittsburgh Epidemiology of Diabetes Complications Study II. Diabetes. 1990 Sep;39(9):1116-24.

33. Ibid.

34. d'Annunzio G, Malvezzi F, Vitali L, Barone C, Giacchero R, Klersy C, Zanette S, Lorini R. Diabet Med. A 3-19-year follow-up study on diabetic retinopathy in patients diagnosed in childhood and treated with conventional therapy. 1997 Nov;14(11):951-8.

35. Younis N, Broadbent DM, Vora JP, Harding SP; Liverpool Diabetic Eye Study. Incidence of sight-threatening retinopathy in patients with type 2 diabetes in the Liverpool Diabetic Eye Study: a cohort study. Lancet. 2003 Jan 18;361(9353):195-200.

36. Klein R, Klein BE, Moss SE, Cruickshanks KJ. The Wisconsin Epidemiologic Study of diabetic retinopathy. XIV. Ten-year incidence and progression of diabetic retinopathy. Arch Ophthalmol. 1994 Sep;112(9):1217-28.

37. Ibid.

38. Cohen O, Norymberg K, Neumann E, Dekel H. Complication-free 
duration and the risk of development of retinopathy in elderly diabetic patients. Arch Intern Med. 1998 Mar 23;158(6):641-4.

39. Zhang X, Norris SL, Saadine J, Chowdhury FM, Horsley T, Kanjilal $\mathrm{S}$, Mangione CM, Buhrmann R. Effectiveness of interventions to promote screening for diabetic retinopathy. Am J Prev Med. 2007 Oct;33(4):318-35. Review.

40. Klein R, Klein BE, Moss SE, Cruickshanks KJ. The Wisconsin Epidemiologic Study of diabetic retinopathy. XIV. Ten-year incidence and progression of diabetic retinopathy. Arch Ophthalmol. 1994 Sep;112(9):1217-28.

41. Mitchell P. Development and progression of diabetic eye disease in Newcastle (1977-1984): rates and risk factors. Aust N Z J Ophthalmol. 1985 Feb;13(1):39-44.

42. [No authors listed] Tight blood pressure control and risk of macrovascular and microvascular complications in type 2 diabetes: UKPDS 38. UK Prospective Diabetes Study Group. BMJ. 1998 Sep 12;317(7160):703-13. Erratum in: BMJ 1999 Jan 2;318(7175):29.

43. Klein R, Moss SE, Klein BE. New management concepts for timely diagnosis of diabetic retinopathy treatable by photocoagulation. Diabetes Care. 1987 Sep-Oct;10(5):633-8.

44. Klein BE, Moss SE, Klein R. Longitudinal measure of glycemic control and diabetic retinopathy. Diabetes Care. 1987 MayJun;10(3):273-7.

45. Bhavsar AR. Diabetic retinopathy. The diabetes eye exam initiative. Minn Med. 2002 Jun;85(6):46-7. No abstract available.

46. Cahill M, Halley A, Codd M, O’Meara N, Firth R, Mooney D, Acheson RW.

Prevalence of diabetic retinopathy in patients with diabetes mellitus diagnosed after the age of 70 years. $\mathrm{Br} \mathrm{J}$ Ophthalmol. 1997 Mar;81(3):218-22.

47. Wong TY, Mwamburi M, Klein R, Larsen M, Flynn H, Hernandez-Medina M, Ranganathan G, Wirostko B, Pleil A, Mitchell P. Rates of progression in diabetic retinopathy during different time periods: a systematic review and meta-analysis. Diabetes Care. 2009 Dec;32(12):2307-13.

48. Porta M, Sjoelie AK, Chaturvedi N, Stevens L, Rottiers R, Veglio M, Fuller JH; EURODIAB Prospective Complications Study Group. Risk factors for progression to proliferative diabetic retinopathy in the EURODIAB Prospective Complications Study. Diabetologia. 2001 Dec;44(12):2203-9.

49. Misra A, Bachmann MO, Greenwood RH, Jenkins C, Shaw A, Barakat O, Flatman M, Jones CD. Trends in yield and effects of screening intervals during 17 years of a large UK communitybased diabetic retinopathy screening programme. Diabet Med. 2009 Oct;26(10):1040-7.

50. Mitchell P. The prevalence of diabetic retinopathy: a study of 1300 diabetics from Newcastle and the Hunter Valley. Aust J Ophthalmol. 1980 Aug;8(3):241-6.

51. Olafsdóttir E, Stefánsson E. Biennial eye screening in patients with diabetes without retinopathy: 10-year experience. Br J Ophthalmol. 2007 Dec;91(12):1599 601. Epub 2007 Jul 12.

52. Diabetes Control and Complications Trial/Epidemiology of Diabetes Interventions and Complications (DCCT/EDIC) Research Group, Nathan DM, Zinman B, Cleary PA, Backlund JY, Genuth S, Miller R, Orchard TJ. Modern-day clinical course of type 1 diabetes mellitus after 30 years' duration: the diabetes control and complications trial/epidemiology of diabetes interventions and complications and Pittsburgh epidemiology of diabetes complications experience (1983-2005). Arch Intern Med. 2009 Jul 27;169(14):1307-16.

53. Moss SE, Klein R, Kessler SD, Richie KA. Comparison between ophthalmoscopy and fundus photography in determining severity of diabetic retinopathy. Ophthalmology. 1985 Jan;92(1):62-7.

54. Hutchinson A, McIntosh A, Peters J, O'Keeffe C, Khunti K, Baker R, Booth A. Diabet Med. Effectiveness of screening and monitoring tests for diabetic retinopathy--a systematic review. 2000 Jul;17(7):495-506.

55. Javitt JC, Aiello LP, Bassi LJ, Chiang YP, Canner JK. Detecting and treating retinopathy in patients with type I diabetes mellitus. Savings associated with improved implementation of current guidelines. American Academy of Ophthalmology. Ophthalmology. 1991 Oct;98(10):1565-73; discussion 1574.

56. Leese G, Broadbent D, Harding S, Vora J. Screening for diabetic retinopathy. Approaching 90\% sensitivity with new techniques. BMJ. $1995 \mathrm{Nov}$ 4;311(7014):1230-1.

57. Gibbins RL, Owens DR, Allen JC, Eastman L. Practical application of the European Field Guide in screening for diabetic retinopathy by using ophthalmoscopy and $35 \mathrm{~mm}$ retinal slides. Diabetologia. 1998 Jan;41(1):59-64.

58. Vujosevic S, Benetti E, Massignan F, Pilotto E, Varano M, Cavarzeran F, Avogaro A, Midena E. Screening for diabetic retinopathy: 1 and 3 nonmydriatic 45-degree digital fundus photographs vs 7 standard early treatment diabetic retinopathy study fields. Am J Ophthalmol. 2009 Jul;148(1):111-8. Epub 2009 May 5.

59. Williams GA, Scott IU, Haller JA, Maguire AM, Marcus D, McDonald HR. Single-field fundus photography for diabetic retinopathy screening: a report by the American Academy of Ophthalmology. Ophthalmology. 2004 May;111(5):1055-62. Review.

60. Boucher MC, Gresset JA, Angioi K, Olivier S. Effectiveness and safety of screening for diabetic retinopathy with two nonmydriatic digital images compared with the seven standard stereoscopic photographic fields. Can J Ophthalmol. 2003 Dec;38(7):557-68.

61. Perrier M, Boucher MC, Angioi K, Gresset JA, Olivier S. Comparison of two, three and four 45 degrees image fields obtained with the Topcon CRW6 nonmydriatic camera for screening for diabetic retinopathy. Can J Ophthalmol. 2003 Dec;38(7):569-74.

62. Fransen SR, Leonard-Martin TC, Feuer WJ, Hildebrand PL; Inoveon Health Research Group. Clinical evaluation of patients with diabetic retinopathy: accuracy of the Inoveon diabetic retinopathy3DT system. Ophthalmology. 2002 Mar;109(3):595-601.

63. Patra S, Gomm EM, Macipe M, Bailey C. Interobserver agreement between 
primary graders and an expert grader in the Bristol and Weston diabetic retinopathy screening programme: a quality assurance audit. Diabet Med. 2009 Aug;26(8):820-3.

64. Whited JD, Datta SK, Aiello LM, Aiello LP, Cavallerano JD, Conlin PR, Horton MB, Vigersky RA, Poropatich RK, Challa P, Darkins AW, Bursell SE. A modeled economic analysis of a digital tele-ophthalmology system as used by three federal health care agencies for detecting proliferative diabetic retinopathy. Telemed J E Health. 2005 Dec;11(6):641-51.

65. Baeza M, Orozco-Beltrán D, Gil-Guillen VF, Pedrera V, Ribera MC, Pertusa S, Merino. J.Int J Clin Pract. Screening for sight threatening diabetic retinopathy using non-mydriatic retinal camera in a primary care setting: to dilate or not to dilate? 2009 Mar;63(3):433-8.

66. Pugh JA, Jacobson JM, Van Heuven WA, Watters JA, Tuley MR, Lairson DR, Lorimor RJ, Kapadia AS, Velez R. Screening for diabetic retinopathy. The wide-angle retinal camera. Diabetes Care. 1993 Jun;16(6):889-95.

67. Virgili G, Menchini F, Dimastrogiovanni AF, Rapizzi E, Menchini U, Bandello F, Chiodini RG. Optical coherence tomography versus stereoscopic fundus photography or biomicroscopy for diagnosing diabetic macular edema: a systematic review. Invest Ophthalmol Vis Sci. 2007 Nov;48(11):4963-73. Review.

68. Browning DJ, Glassman AR, Aiello LP, Bressler NM, Bressler SB, Danis RP, Davis MD, Ferris FL, Huang SS, Kaiser PK, Kollman C, Sadda S, Scott IU, Qin H; Diabetic Retinopathy Clinical Research Network. Optical coherence tomography measurements and analysis methods in optical coherence tomography studies of diabetic macular edema. Ophthalmology. 2008 Aug;115(8):1366-71, 1371.e1.

69. Koleva-Georgieva DN, Sivkova NP. Optical coherence tomography for the detection of early macular edema in diabetic patients with retinopathy. Folia Med (Plovdiv). 2010 Jan-Mar; 52(1):40-8.

70. Hannouche RZ, Avila MP. Retinal thickness measurement and evaluation of natural history of the diabetic macular edema through optical coherence tomography. Arq Bras Oftalmol. 2009 Jul-Aug;72(4):433-8.

71. Browning DJ, Fraser CM, Propst BW. The variation in optical coherence tomography-measured macular thickness in diabetic eyes without clinical macular edema. Am J Ophthalmol. 2008 May;145(5):889-93. Epub 2008 Mar 10.

72. Browning DJ, Glassman AR, Aiello LP, Bressler NM, Bressler SB, Danis RP, Davis MD, Ferris FL, Huang SS, Kaiser PK, Kollman C, Sadda S, Scott IU, Qin H; Diabetic Retinopathy Clinical Research Network. Optical coherence tomography measurements and analysis methods in optical coherence tomography studies of diabetic macular edema. Ophthalmology. 2008 Aug;115(8):1366-71, 1371.e1.

73. ETDRS Study Group. Treatment techniques and clinical guidelines for photocoagulation of diabetic macular edema (ETDRS Report Number 2). Ophthalmology. 1987; 94(7): 761-74.

74. Stratton IM, et al. Association of glycaemia with macrovascular and microvascular complications of type 2 diabetes (UKPDS 35): prospective observational study. BMJ 2000; 321: 405-12.

75. The Diabetes Control and Complications Trial Research Group. Effect of pregnancy on microvascular complications in the Diabetes Control and Complications Trial. Diabetes Care 2000; 23: 1084-91.

76. The Diabetes Control and Complications Trial Research Group. Early worsening of retinopathy in the Diabetes Control and Complications Trial. Arch Opthalmol. 1998; 116: 874-86.

\section{Appendix: Diabetic Retinopathy (DR) Disease Severity Scale}

\section{No Apparent Diabetic Retinopathy}

Non-proliferative Diabetic Retinopathy (NPDR)

- Mild to moderate NPDR - microaneurysms, intra-retinal hemorrhages, hard exudates, foveal avascular zone abnormalities

- Moderate to severe NPDR - cotton wool spots, venous beading, intra-retinal microvascular abnormalities (IRMA)

- Severe NPDR (4-2-1 rule) - any one of: severe $(>20)$ intra-retinal hemorrhages in each of four quadrants; definite venous beading in two or more quadrants; prominent IRMA in one or more quadrant(s)

- Very severe NPDR - any two of the above criteria

Proliferative Diabetic Retinopathy (PDR) - one or more of:

- Neovascularization of the disc - NVD (particularly greater than 1 disc diameter in size)

- Neovascularization elsewhere - NVE
- Vitreous/pre-retinal hemorrhage

- Neovascularization of the iris - NVI (anterior segment neovascularization)

Clinically Significant (Diabetic) Macular Edema (CSME)

- Any retinal thickening within 500 microns of the center of the macula (fovea), or;

- Retinal thickening at least one disc area in size, any part of which is within one disc diameter of the center of the macula (fovea), or;

- Hard exudates within 500 microns of the center of the macula (fovea) with adjacent retinal thickening.

It is important to note that hard exudates are a sign of current or previous macular edema. CSME may be focal (leakage from micro-aneurysms or IRMA) or diffuse (leakage from the underlying capillary bed). CSME is the most common cause of decreased vision and blindness among patients with diabetes, and may occur concurrent with any stage of diabetic retinopathy. 